\title{
Effects of elevated nest box temperature on incubation behaviour and offspring fitness-related traits in the Collared Flycatcher Ficedula albicollis
}

\author{
Aneta Arct ${ }^{1,2}$ (D) $\cdot$ Rafał Martyka $^{1,3} \cdot$ Szymon M. Drobniak ${ }^{4,5} \cdot$ Wioleta Oleś $^{4} \cdot$ Anna Dubiec $^{6} \cdot$ Lars Gustafsson $^{1}$
}

Received: 28 April 2021 / Revised: 13 November 2021 / Accepted: 19 November 2021 / Published online: 9 December 2021

(c) The Author(s) 2021

\begin{abstract}
Ambient temperature experienced by an animal during development or subsequently as an adult can affect many aspects of its behaviour and life-history traits. In birds, egg incubation is a vital component of reproduction and parental care. Several studies have suggested that environmental factors (such as nest microclimate) can influence the ability of incubating parents to maintain suitable conditions for embryo development. Here, we manipulated the developmental conditions of embryos through a modification of nest box thermal microclimate to investigate female incubation behaviour and its impact on offspring fitness-related traits in a wild population of the Collared Flycatcher (Ficedula albicollis). The temperature in experimental nests was increased using a heat-pack placed under the roof of a nest box, resulting in an average temperature increase of $2.5^{\circ} \mathrm{C}$, which corresponds to projected climate change scenarios. We demonstrated that females from nests with elevated temperature spent less time in the nest box during egg incubation and had more off-bouts than females from control nests. Moreover, we found that offspring from the experimentally heated nests had larger body mass at fledging in comparison to the control ones. Our study indicates that nest microclimate during the incubation period affects female incubation behaviour and offspring quality, indicating that environmental variation in nest temperature early in ontogeny can have important and long-lasting fitness consequences.
\end{abstract}

Keywords Reproductive success $\cdot$ Parental care $\cdot$ Nest microclimate $\cdot$ Environmental temperature $\cdot$ Birds

\section{Zusammenfassung}

Auswirkungen einer erhöhten Nistkastentemperatur auf das Brutverhalten und auf Fitness-relevante Eigenschaften der Jungen des Halsbandschnäppers (Ficedula albicollis)

Die Umgebungstemperatur, der ein Tier während seiner Entwicklung oder später als Adulter ausgesetzt ist, kann viele Aspekte seines Phänotyps, seines Verhaltens und seiner Eigenschaften über das ganze Leben hinweg beeinflussen. Bei Vögeln ist das Ausbrüten der Eier ein wichtiger Bestandteil der Fortpflanzung und der elterlichen Fürsorge. Einige Untersuchungen haben gezeigt, dass Umweltfaktoren (insbesondere das Mikroklima im Nest) die Fähigkeit der brütenden Elterntiere beeinflussen können, geeignete Bedingungen für die Entwicklung des Embryos aufrechtzuerhalten. Hierfür

Communicated by S. Bouwhuis.

Aneta Arct

aneta.arct@gmail.com

1 Animal Ecology, Department of Ecology and Genetics, Evolutionary Biology Centre, Uppsala University, Norbyvägen 18D, 75236 Uppsala, Sweden

2 Institute of Systematics and Evolution of Animals, Polish Academy of Sciences, ul. Sławkowska 17, 31-016 Kraków, Poland

3 Institute of Nature Conservation, Polish Academy of Sciences, Mickiewicza 33, 31-120 Kraków, Poland
4 Institute of Environmental Sciences, Jagiellonian University, Gronostajowa 7, 30-387 Kraków, Poland

5 Evolution \& Ecology Research Centre; School of Biological, Environmental \& Earth Sciences, University of New South Wales, Kensington 2052, Australia

6 Museum and Institute of Zoology, Polish Academy of Sciences, Wilcza 64, 00-679 Warsaw, Poland 
manipulierten wir die Bedingungen während der Entwicklung der Embryos durch eine Veränderung des Mikroklimas (Temperatur) in den Nistkästen, um das Brutverhalten der Weibchen und mögliche Auswirkungen auf die Fitness der Nachkommen in einer Freilandpopulation des Halsbandschnäppers (Ficedula albicollis) zu untersuchen. Die Temperatur in den Versuchsnestern wurde mit Hilfe einer Wärmepackung unter dem Dach der Nistkästen erhöht und führte zu einem durchschnittlichen Temperaturanstieg von $2,5^{\circ} \mathrm{C}$. Unseres Wissens ist dies das erste Temperatur-Experiment an einer wildlebenden Vogelpopulation, das von einem realistischen Szenario der globalen Erwärmung im 21. Jahrhundert ausgeht. Wir konnten zeigen, dass Weibchen aus Nestern mit erhöhter Temperatur während der Bebrütung der Eier weniger Zeit im Nistkasten verbrachten und mehr Auszeiten hatten als Weibchen aus den Kontrollnestern. Darüber hinaus stellten wir fest, dass die Jungen aus den experimentell beheizten Nestern beim Ausfliegen eine größere Körpermasse aufwiesen als die aus den Kontrollnestern. Unsere Studie zeigt, dass sich das Mikroklima im Nest während der Brutzeit auf das Brutverhalten der Weibchen und die Qualität des Nachwuchses auswirkt, was darauf hindeutet, dass Schwankungen in der Nesttemperatur in der frühen Phase der Ontogenese wichtige und lang anhaltende Auswirkungen auf die Fitness der Jungen haben können.

\section{Introduction}

Climate change models predict a warmer climate and greater variability in weather components, such as temperature or rainfall, across the world in the coming decades. Our knowledge of the ecological responses to climate change in different organisms is still developing (Dunn et al. 2010; du Plessis et al. 2012; Halupka and Halupka 2017). Understanding the responses of animals to changing environments is essential to predicting the extent to which populations and species will adapt to a rapidly changing world. Birds provide an excellent model system to study such impacts on life-history traits. Avian incubation, as a vital component of parental care heavily dependent on thermal conditions, provides a particularly suitable system in which trade-offs between investment in egg heating and adult self-maintenance may be studied (Deeming 2002; Lundblad and Conway 2021) in the context of changing temperature conditions.

Ambient temperature influences energy expenditure during incubation, because at lower ambient temperatures, incubation efficiency must be increased to keep eggs within temperature ranges suitable for successful embryo development. Females may respond to this limitation by optimizing their incubation rhythm (Conway and Martin 2000a, b). The incubation rhythm consists of alternating periods where females leave the clutch to obtain food (off-bouts) and return to re-warm the eggs (on-bouts; Deeming 2002). Egg temperature at the incubation stage and its variation can influence embryonic development and affect numerous offspring fitness-related traits (reviewed in DuRant et al. 2013a). In particular, ambient temperature is commonly expected to influence avian incubation behaviour (Conway and Martin 2000a, b). However, despite the critical role that incubation plays in avian reproduction, few experimental studies have examined the relationship between temperature in the nest and incubation behaviour in natural systems and relatively similar manipulations resulted in opposite results
(Bryan and Bryant 1999; Nilsson et al. 2008; Pérez et al. 2008; Ardia et al. 2009; Ardia et al. 2010; Álvarez and Barba 2014; Coe et al. 2015; Vaugoyeau et al. 2017). Virtually, all previous attempts did that by directly applying thermal manipulations to the eggs, thus creating largely unnatural conditions that factor out female behaviour-which can be an important modulator of the in-nest thermal conditions. Moreover, when it comes to the impact of increasing temperature in relation to the climate change, most previous experiments used unrealistic temperature increases, not corresponding to projected climate scenarios. Climate models predict increases in mean temperature (between 1.5 and $3{ }^{\circ} \mathrm{C}$ in the twenty-first century; Meehl et al. 2000; Pachauri et al. 2014; IPCC 2020) across most of the lands-a degree of heating rarely applied as thermal manipulation in bird incubation studies. Therefore, we need more information on how biologically realistic increases in ambient temperature (and consequently — changes to the overall nest thermal microclimate) could affect the incubation behaviour of females, with cascading effects on the offspring.

Impacts of thermal conditions during incubation on offspring traits are well documented. Changes in embryonic temperature may alter developmental trajectories (Olson et al. 2008) to ultimately constrain or improve offspring fitness-related traits (DuRant et al. 2013a). Indeed, some studies showed that temperature during early embryonic development at the incubation stage has potential to affect the physiological maturation, structural size and immunocompetence (Hepp et al. 2006; Hopkins et al. 2011; Nord and Nilsson 2011; DuRant et al. 2013b; Griffith et al. 2016; Vaugoyeau et al. 2017; Andreasson et al. 2018). Such alterations may in turn affect condition and survival of offspring (Berntsen and Bech 2016). However, experimental studies that simultaneously investigate female incubation behaviour and offspring fitness-related traits with respect to external thermal conditions are scarce in songbirds (Pérez et al. 2008; Ardia et al. 2009; Álvarez and Barba 2014; Coe et al. 2015; Vaugoyeau et al. 2017). 
Here, we manipulated the developmental conditions of bird embryos by experimentally changing the inner nest box temperature during incubation to investigate the effects of in-nest pre-hatching temperature changes on female incubation behaviour and offspring fitness-related traits. We chose this form of thermal manipulation instead of heating the eggs to create more realistic manipulated conditions that factor in female behaviour and better reflect impacts of ambient temperature increases caused by climate warming. The study was performed in a wild population of the Collared Flycatcher Ficedula albicollis. Hole-nesting birds, readily breeding in provided nest boxes, offer a perfect system for studying incubation-related patterns and processes. We predicted that temperature in the nest box would explain variation in female incubation behaviour. Specifically, we predicted that females should decrease incubation effort in heated nests but not in control ones. Moreover, we sought to determine whether elevated temperature in the nest during incubation influences fledglings' body mass and tarsus length. Embryos developing in higher ambient temperature in the nest can expend less energy and potentially hatch with more energy reserves (Larsen et al. 2003). Therefore, we expected that nestlings hatched in heated nests would be heavier and have larger structural size at fledging.

\section{Methods}

\section{Study area}

The field study was carried out during two breeding seasons in years 2018 and 2019. Study plots with nest boxes were located in the southern part of the island of Gotland, Sweden $\left(57^{\circ} 03^{\prime} \mathrm{N}, 18^{\circ} 17^{\prime} \mathrm{E}\right)$. Collard flycatchers breed there in standard wooden nest boxes $(29 \times 10 \times 10 \mathrm{~cm}, 3.2-\mathrm{cm}$ diameter entrance hole) placed on tree at approximately $1.3 \mathrm{~m}$ above ground level in a grid of 30-50 m between adjacent boxes. Collared flycatchers on Gotland usually lay one clutch per year, consisting of six eggs on average (range 4-8 eggs) that hatch in the beginning of June. Females lay one egg per day and the incubation is expected to start at the day when the female has laid her final egg (Koski et al. 2020). The first eggs are laid in the first half of May and incubation is undertaken solely by females. Nestlings hatch after approximately 14 days of incubation and remain in the nests for additional 14-16 days, fed by both parents. They reach the maximum body mass at the age of 10-11 days and lose some mass prior to fledging. After fledging, young collared flycatchers stay close to the nest for 2 weeks and are still fed by parents.

During each breeding season (May-June), all breeding attempts were regularly monitored. Regular nest box checks (every 4 days) from the beginning of May established the date of clutch initiation. From the fifth egg onwards (assuming one egg was laid per day), the checks were continued every other day to determine clutch size. Nests where incubation had already started (day of incubation start $=$ day 0 of incubation) were visited every third day to perform experimental procedures. After hatching (hatching day $=$ day 0 of nestling life), nests were visited on days 2nd and 12th to obtain nestling measurements.

As many adult birds as possible were caught using cliptraps or mist-nets, and (if not already ringed) marked with a numbered aluminium ring. The females were caught, while incubating (at least the 6th day of incubation), while males were caught while feeding the nestlings between day 6 and 12 after hatching. Birds were aged based on a distinctive moult limit visible within the greater wing coverts, wear of primaries and the colouration of the inside of upper mandible, and in most cases, their age was confirmed based on the past ringing data. Sex was determined based on plumage characteristics (Svenson 1992). Each year, basic nestling measurements were recorded: body mass on days 2 and 12 , tarsus length on day 12 and the number of successfully fledged offspring. The number of successfully fledge offspring was assessed by checking for any dead unfledged individuals between days 16 and 18 after hatching. Blood samples (ca. $20 \mu \mathrm{l}$ ) were collected from all nestlings on day 2 and stored in $96 \%$ ethanol for further genetic analyses. DNA was extracted from blood samples with QIAamp DNA Blood Mini Kit according to a standard protocol. Sexing of nestlings was performed via PCR using the P2-P8 primers (Griffiths et al. 1998) that amplify the fragments of sexspecific CHD locus.

\section{Experimental procedure}

A total of 40 nests ( 20 heated and 20 control) of the Collared Flycatcher were used in each of breeding season. On the first day of incubation (we recognized incubation when eggs were warm), half of randomly selected nests were assigned to the heated group (experimental nests) and the other half remained unmanipulated (control nests). We tried to create dyads of nests with the same laying date and similar clutch size ( \pm 1 egg). Experimental nests were supplied with active heat-packs (Aqua pack-heat-pack $72 \mathrm{~h}$, size $15.5 \times 11.0 \mathrm{~cm}$, producing heat through the oxidation of iron powder, HEATPACK.de). We fixed the heat-packs to the inner side of a nest box roof, thus suspending it approx. $20 \mathrm{~cm}$ above the flycatcher nest. Inactive (exhausted) heat-packs were installed in control nest boxes in the same way. Heated nests were visited every $72 \mathrm{~h}$ to change the heat-packs; control nests were visited with the same frequency. To remove additional sources of variation, in both experimental and control nests, we standardized the height of the nest (to $\sim 12 \mathrm{~cm}$ ) by modifying the amount of nesting material in the lower part of the nest. We manipulated the temperature inside the nest box 
throughout the whole incubation period. Temperatures in nests-boxes were monitored in both experimental and control nests to make sure that thermal manipulation was effective. To achieve this, nest boxes were fitted with temperature sensors (Thermochron iButton DS1923; 6×17 mm, temperature range: -20 to $85^{\circ} \mathrm{C}$; resolution $0.0625^{\circ} \mathrm{C}$ ) attached to the wall of the nest box approximately $5 \mathrm{~cm}$ above the nest cup. Temperature has been recorded every 15 min during the experimental period in the control and experimental boxes.

\section{Incubation behaviour analysis}

We collected data on incubation behaviour only in 2019. In total, incubation rhythm was followed in 21 females: 11 from control nests and 10 from heated nests. On day 6 of the incubation period, temperature loggers (Thermochron iButtons) were placed in nests among the eggs. The technique based on the iButton temperature logger provided reliable and accurate measurement of female incubation behaviour in previous studies (Amininasab et al. 2016; Bueno-Enciso et al. 2017). The female nest attentiveness data obtained using the camera were highly correlated with the data obtained using temperature logger data (see details in Amininasab et al. 2016; Bueno-Enciso et al. 2017). The loggers stayed there for the whole following day and were removed on the subsequent day. To analyse incubation behaviour, we used records from only one day (i.e., day 7 of incubation). The loggers were set to record temperature in 2-min intervals. Such interval is suitable to assess female incubation behaviour based on fluctuations of temperature measured in the nest cup (Capilla-Lasheras 2018). Due to a limited number of loggers, we were not able to get data on longer periods of incubation. We did not find the loggers to be removed from nests by females. To get data on incubation behaviour for each female, we applied the 'incR' package implemented in $\mathrm{R}$, version 4.0.3 (Capilla-Lasheras 2018; R Core Team 2020). The package allows to automatically extract data on presence or absence of an incubating female (so-called onbouts and off-bouts) based on the nest and ambient temperatures at every time point along an incubation time series. As we had a limited number of loggers, we could not record ambient temperatures using loggers. Therefore, we used data from a nearby weather station (Visby Airport Station) where temperature was recorded every $20 \mathrm{~min}$ (https://www. wunderground.com/history/daily/se/visby/ESSV/date/20194-28). Nevertheless, we were able to perform the analysis, because incubation scoring is performed based on averaged (per hour) ambient temperature (Capilla-Lasheras 2018). Ambient temperature was much lower than incubation temperature and they did not overlap with each other, excluding the problem with larger measurement intervals of ambient temperatures. Before running automated scoring of incubation behaviour using the 'incR' package, we had set several user-defined parameters. First, we fixed parameters lower. time and upper.time [which determine a time window when a female is assumed to be always incubating (i.e. for diurnal birds the window is in the night)] at 2200 and 0300, respectively. We had also fixed the parameter temp.diff.threshold that controls for a difference which is allowed between nest and ambient temperature at $4{ }^{\circ} \mathrm{C}$. The sensitivity parameter, that allows to reduce the off-bout threshold when incubation temperature is close to ambient temperature, was fixed at 0.25 . The maxNightVariation parameter, which determines the maximum variation allowed in the lower.time-upper.time window and controls for big drops in nest temperature during that temporal window, was set to $2{ }^{\circ} \mathrm{C}$. All parameters were set up based on recommendations validated by CapillaLasheras (2018). We generated four variables that were in the focus of our interest, i.e., egg incubation temperature, percentage time spent in the nest by incubating females, and the number and averaged duration of off-bouts. All those variables referred to a period between 3 a.m. and 10 p.m.

\section{Statistical analyses}

All analyses were performed in the R environment, ver. 4.0.3 (R Core Team 2020). To compare control and heated nests in respect to egg incubation temperature, percentage time spent by incubating females in the nest, the number and averaged duration of off-bouts made by incubating females, we performed independent $t$ tests. To examine differences in hatching success (expressed as the proportion unhatched eggs in relation to all laid eggs in a brood) between control and heated nests, we fitted a GLM (generalized linear model) with treatment and year as fixed factors, and a logitlink function. To analyse body mass on day 2 and 12 after hatching and tarsus length on day 12 in the offspring, we fitted linear mixed models (LMMs) using the 'Ime4' package, ver. 1.1.25 (Bates et al. 2015). To analyse offspring survival in period from hatching day to day 12 after hatching we fitted a generalised linear mixed model (GLMM) with binomial error variance and logit-link function using the same 'Ime4' package (Bates et al. 2015). All initial models included the treatment (control vs. heated nests), offspring sex (female vs. male) and year (2018 vs. 2019) as categorical factors, whereas hatching date, brood size, tarsus length (only in the model analysing body mass on day 12) and body mass on day 2 after hatching (only in the model analysing offspring survival) were included as continuous covariates. Female identity was introduced to models as a random factor. To reduce initial models, we removed nonsignificant covariates (if $P>0.10$ ), starting from the least significant term. To test fixed effects in LMMs, we used $F$-tests with the degrees of freedom approximated by the Kenward-Roger method, by applying the 'pbkrtest' package, ver. 0.4.8, and 'ImerTest' package, ver. 3.1.3 (Halekoh and 
Hojsgaard 2014; Kuznetsova et al. 2017). The least square means with SEs for categorical variables were estimated from the final models using the 'emmeans' package, ver. 1.5.2 (Lenth 2020). In case of the GLMM, fixed effects were examined using the Wald $\chi^{2}$ test. To visualise differences in means between control and heated nests we employed the 'ggplot2' package, ver. 3.3.2 (Wickham 2016). In all analyses with Gaussian error variance, we visually checked for normality and homogeneity of residuals. If necessary, the dependent variable was log-transformed and the information on that is included in "Results". All statistical tests were two-tailed with the significance level set at $P<0.05$. There are differences in sample sizes among analyses because of nest abandonment or missing measurements. We provide means \pm SE in the "Results" section; in case of transformeddependent variables, back-transformed values on original scale are presented.

\section{Results}

Below, every time we report on results concerning temperature measurements, we refer to the following temperature parameters named in a consistent way: ambient temperature-measured by the weather station in Visby; nest box temperature or ambient temperature in the nest-measured with an iButton placed on the nest box wall; incubation temperature-measured in the nest cup during incubation.

\section{Pre-treatment effects}

Females assigned to control and experimental groups did not differ in body mass measured at the 6th day of incubation (linear model controlling for year effect; treatment: $F_{1,55}=1.02, P=0.32$, year: $F_{1,55}=2.59, P=0.11$ ). Control and experimental broods also did not differ in laying date (linear model controlling for year effect; treatment: $F_{1,76}=0.00, P=0.96$, year: $\left.F_{1,76}=74.48, P<0.001\right)$ and clutch size (liner model controlling for year effect; treatment: $F_{1,76}=0.01, P=0.92$, year: $\left.F_{1,76}=8.86, P=0.004\right)$.

\section{Effect of experimental procedure on nest box temperature}

Our manipulation of the level of temperature in the nest was successful; temperature measured inside the nest box was higher in heated compared to control nests by $2.5^{\circ} \mathrm{C}$ (linear model controlling for year effect; treatment: $F_{1,59}=28.27$, $P<0.001$, year: $F_{1,59}=2.71, P=0.10 ;$ mean \pm SE for heated vs. control nests: $17.4 \pm 0.3$ and $14.9 \pm 0.3{ }^{\circ} \mathrm{C}$ ). Differences in temperature detected inside nest boxes between heated and control nests were observed in both breeding seasons, and temperature detected outside the nest boxes was always lower compared to temperatures observed inside the nest boxes (Fig. 1). Furthermore, the analysis of maximum temperatures noted inside the nest boxes showed similar pattern; maximum temperatures in heated nest boxes were also higher than in control nest boxes (linear model controlling for year effect; treatment: $F_{1,59}=11.11, P=0.001$, year: $F_{1,59}=9.27, P=0.003$; mean $\pm \mathrm{SE}$ for heated vs. control nests: $22.2 \pm 0.5$ and $19.9 \pm 0.5^{\circ} \mathrm{C}$ ).
Fig. 1 Differences in temperature detected inside nest boxes between heated and control nests and temperature detected outside the nest boxes in 2018 and 2019. Sample sizes are presented above bars

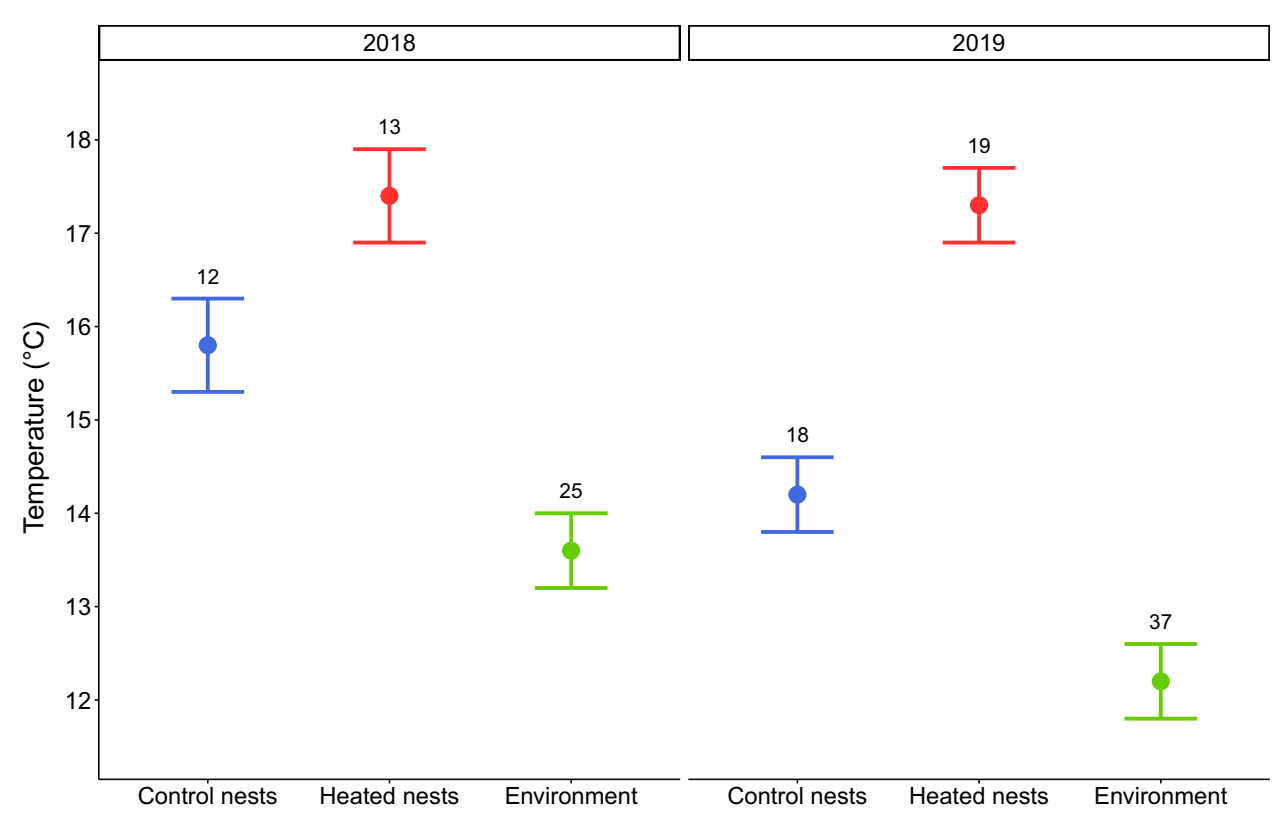




\section{Effects of treatment on female incubation behaviour}

Elevated temperature in the nest box did not affect egg incubation temperature [log-transformed variable, $t_{19}=-0.38, P=0.71$; control vs. heated nests: $34.8 \pm 0.3{ }^{\circ} \mathrm{C}$ (range $32.6-35.4$ ) and $34.9 \pm 0.3{ }^{\circ} \mathrm{C}$ (range 33.6-35.9)]. However, we found that incubating females spent more time in control nests compared to heated nests [log-transformed variable, $t_{19}=-2.93, P=0.009$; control vs. heated nests: $84.8 \pm 1.7 \%$ (range $78.3-96.7$ ) and $79.8 \pm 0.8 \%$ (range 75.7-84.3); Fig. 2]. Moreover, females from heated nests had more off-bouts during incubation than females from control nests $\left(t_{19}=-2.56, P=0.019\right.$; control vs. heated nests: $37.2 \pm 3.8$ (range $10-51$ ) and $50.9 \pm 3.8$ (range $32-71$ ); Fig. 3). The mean duration of off-bout did not differ between females that incubated eggs in control and heated nests $\left[t_{19}=-0.58, P=0.57\right.$; control vs. heated nests: $5.6 \pm 0.2 \mathrm{~min}$. (range 4.7-6.7) and $5.9 \pm 0.3 \mathrm{~min}$. (range $4.8-8.0)$ ].

\section{Effects of treatment on hatching success}

The manipulation of temperature inside the nest boxes during incubation period did not affect hatching success as indicated by lack of differences in the proportion of unhatched eggs among control and experimental nests (treatment: $F_{1,61}=0.87, P=0.36$, year: $F_{1,61}=0.00$,

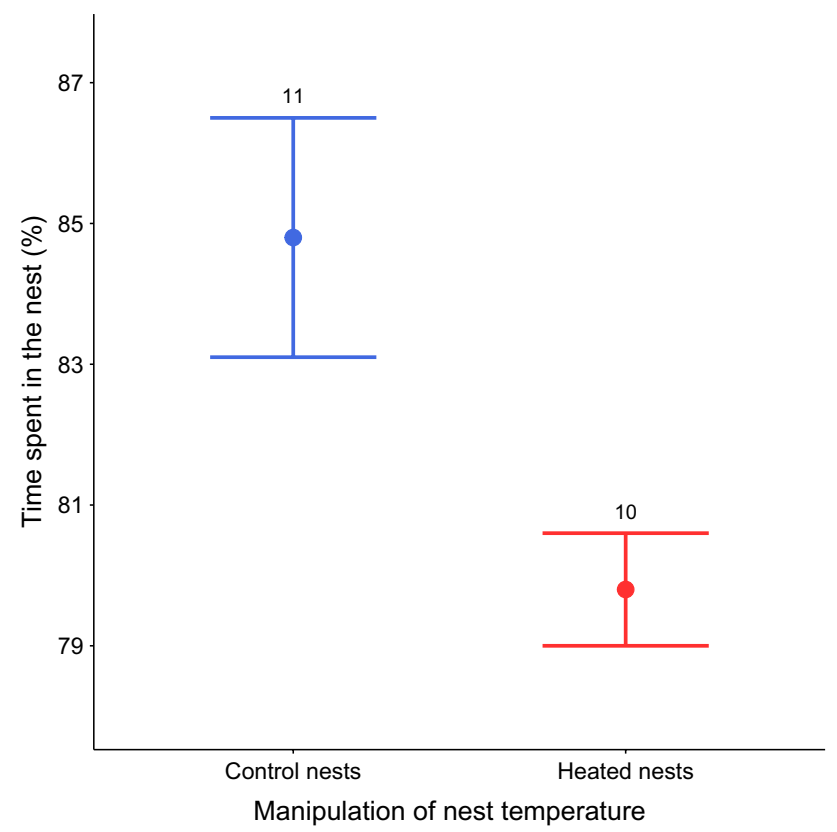

Fig. 2 The effect of manipulation of nest temperature on time spent in the nest by incubating females. Back-transformed (from logarithm) means with SEs are shown. Sample sizes are presented above bars

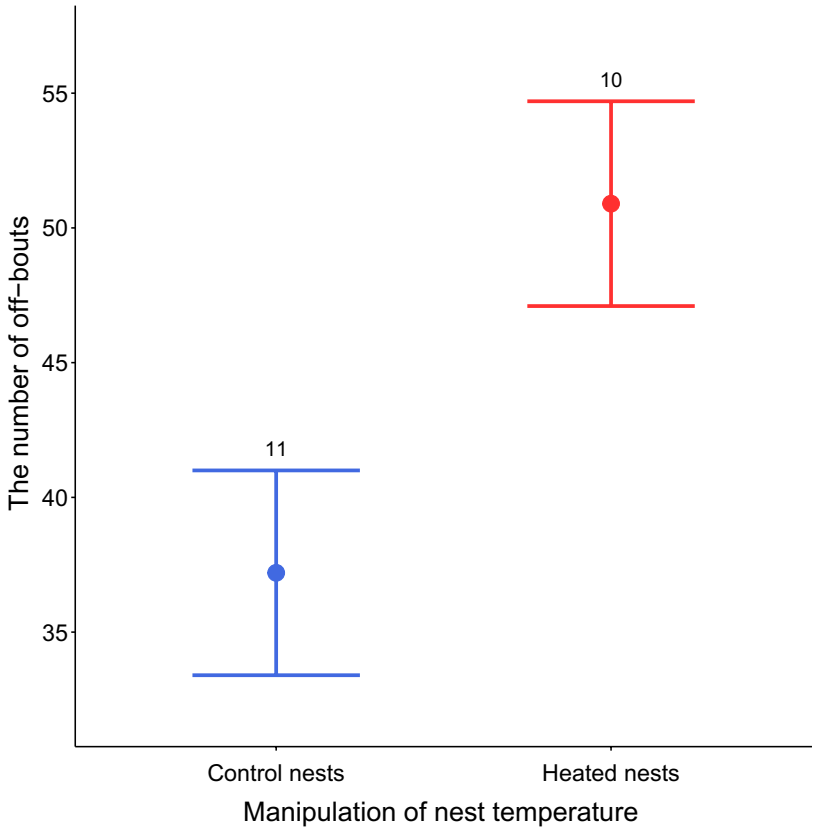

Fig. 3 The effect of manipulation of nest temperature on the number of off-bouts made by incubating females. Means with SEs are shown. Sample sizes are presented above bars

$P=0.98 ;$ control vs. heated nests: $0.16 \pm 0.04$ vs. $0.11 \pm 0.04)$.

\section{Effects of treatment on offspring body mass and structural size}

Body mass of nestlings on day 2 after hatching was not affected by the treatment, offspring sex, year, hatching date and brood size (Table 1). In contrast, we found that nestling body mass measured on day 12 after hatching was significantly affected by manipulation of nest temperature. Offspring reared in heated nest were heavier compared to offspring reared in control nests (Table 1, Fig. 4). Nestling tarsus length on day 12 after hatching was not influenced by the treatment, sex and year (Table 1).

\section{Effects of treatment on offspring survival}

Offspring survival until day 12 after hatching was not affected by heating treatment (Wald $\chi_{1}^{2}=0.00, P=0.99$; $N=265$ ), the year of study (Wald $\chi_{1}^{2}=0.81, P=0.37$ ), brood size (Wald $\chi_{1}^{2}=0.11, P=0.074$, statistics at dropping from model), and hatching date (Wald $\chi_{1}^{2}=0.27, P=0.60$, statistics at dropping from model). However, we found that male nestlings survived better than female nestlings (Wald $\chi_{1}^{2}=5.92, P<0.015$; the proportion of survived males and females: $0.93 \pm 0.02$ vs. $0.63 \pm 0.04$ ), and nestling body mass 
Table 1 Results of a linear mixed models analysing effects of manipulation of nest box temperature during the incubation period on nestling body mass (day 2 and 12) and tarsus length (day 12)

\begin{tabular}{|c|c|c|c|c|}
\hline Model & Estimate & d.f. & $F$ & $P$ \\
\hline \multicolumn{5}{|c|}{ Nestling body mass on day $2(N=265)$} \\
\hline Intercept & $3.05 \pm 0.16$ & & & \\
\hline Treatment & $0.10 \pm 0.20$ & $1,47.3$ & 0.24 & 0.63 \\
\hline Offspring sex & $0.10 \pm 0.08$ & $1,234.5$ & 1.44 & 0.23 \\
\hline Year & $-0.03 \pm 0.21$ & $1,47.3$ & 0.03 & 0.87 \\
\hline Female identity & $0.65(0.50,0.80)$ & & & \\
\hline$R_{\text {marginal }}^{2} / R_{\text {conditional }}^{2}$ & $0.01 / 0.60$ & & & \\
\hline \multicolumn{5}{|c|}{ Nestling body mass on day $12(N=210)$} \\
\hline Intercept & $19.71 \pm 3.85$ & & & \\
\hline Treatment & $0.60 \pm 0.29$ & $1,38.4$ & 4.37 & 0.043 \\
\hline Offspring sex & $-0.15 \pm 0.15$ & $1,191.6$ & 1.01 & 0.31 \\
\hline Year & $1.01 \pm 0.38$ & $1,57.2$ & 7.11 & 0.010 \\
\hline Hatching date & $-0.20 \pm 0.05$ & $1,92.7$ & 14.75 & $<0.001$ \\
\hline Brood size & $-0.40 \pm 0.11$ & $1,57.7$ & 12.28 & $<0.001$ \\
\hline Tarsus length & $0.56 \pm 0.12$ & $1,195.8$ & 20.11 & $<0.001$ \\
\hline Female identity & $0.78(0.53,0,97)$ & & & \\
\hline$R_{\text {marginal }}^{2} / R_{\text {conditional }}^{2}$ & $0.32 / 0.60$ & & & \\
\hline \multicolumn{5}{|c|}{ Nestling tarsus length on day $12(N=211)$} \\
\hline Intercept & $16.80 \pm 0.10$ & & & \\
\hline Treatment & $0.10 \pm 0.12$ & $1,36.8$ & 0.70 & 0.41 \\
\hline Offspring sex & $-0.01 \pm 0.08$ & $1,203.6$ & 0.02 & 0.90 \\
\hline Year & $0.10 \pm 0.12$ & $1,36.9$ & 0.67 & 0.42 \\
\hline Female identity & $0.29(0.16,0.39)$ & & & \\
\hline$R_{\text {marginal }}^{2} / R_{\text {conditional }}^{2}$ & $0.01 / 0.23$ & & & \\
\hline
\end{tabular}

Treatment (control vs. heated nests), offspring sex (female vs. male) and year (2018 vs. 2019) were entered to models as categorical factors while hatching date, brood size and tarsus length (only model analysing body mass on day 12) as covariates. Female identity was introduced to models as a random factor. Presented are final models after removing non-significant covariates (if $P>0.1$ ). Parameter estimates for intercept and fixed effects are accompanied with SE, whereas a random factor is given with $95 \%$ CIs. Marginal and conditional $R^{2}$ is presented for each model on day 2 after hatching positively predicted the probability of offspring survival (Wald $\chi_{1}^{2}=8.47, P<0.004$ ).

\section{Discussion}

We demonstrated that ambient temperature in the nest during incubation had a significant effect on both female incubation behaviour and offspring performance in the collared flycatcher. Specifically, in line with our prediction, we found that females from experimentally heated nests spent less time in the nest and had more off-bouts during incubation than females from control nests. Simultaneously, we showed that females from both control and experimental nests spent similar time on off-bouts, which could be easily explained by the fact that off-bout duration may be constrained to minimize rewarming eggs costs (Biebach 1986; Reid et al. 2000).

Similar to the previous studies, we showed that behaviour of incubating females and ultimately their incubation effort are particularly sensitive to nest microclimate (Conway and
Martin 2000a, b; Cresswell et al. 2003; Olson et al. 2008, van de Ven et al. 2020, Lundblad and Conway 2021). Several studies examined the relationship between ambient temperature and incubation behaviour in birds, and the one frequent finding is that the lower temperatures caused females to spend less time off the nest per bout (Conway and Martin, 2000a, b; Ardia et al. 2010; Boulton et al. 2010; Amininasab et al. 2016). Moreover, a few studies have shown that higher ambient temperatures can be associated with reduced incubation period (Ardia et al. 2006) and increased off-bout duration (Conway and Martin 2000a, b; Camfield and Martin 2009; Boulton et al. 2010). In contrast, Pérez et al. (2008) experimentally heated eggs of the tree swallow (Tachycineta bicolor) during incubation by an average of $6.9^{\circ} \mathrm{C}$ and showed that in boxes with elevated temperature females increased time spent in the nest during incubation. Nevertheless, it is difficult to explain these mixed results, since they used drastically different thermal regimes.

In our study, an increase in temperature within a nest box by $2.5^{\circ} \mathrm{C}$ on average reduced the time spent in the nest 


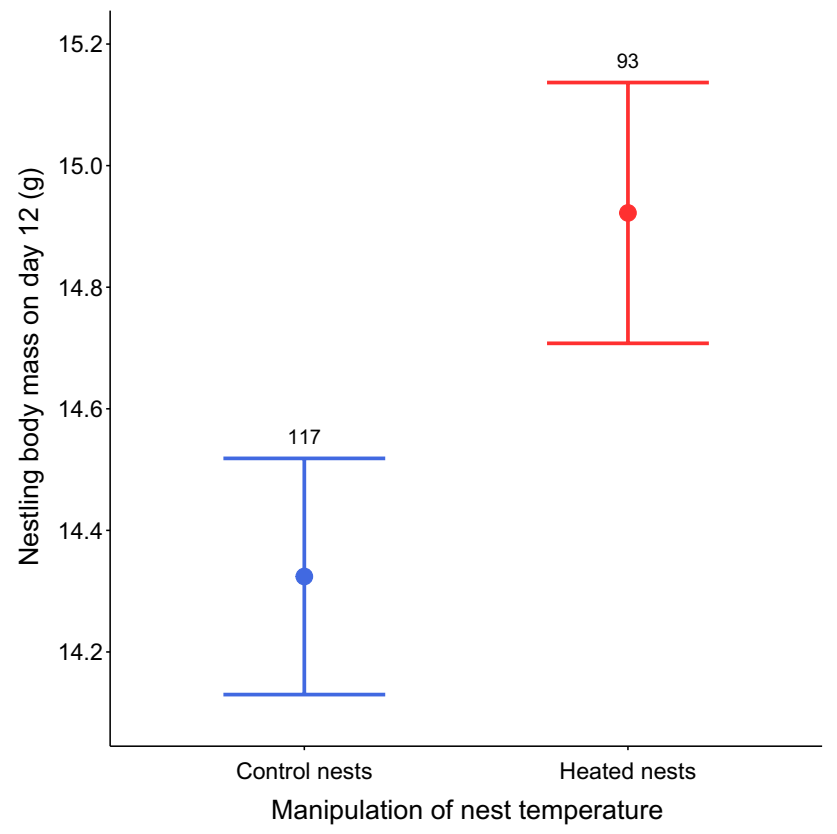

Fig. 4 The effect of manipulation of nest temperature on body mass of 12-day-old nestlings. Least square means with SEs are shown. Sample sizes are presented above bars

by incubating females. Moreover, this change in incubation behaviour may be attributed to reduced energetic demands exerted on females due to relatively less heat being transferred to eggs, allowing them to forage for longer periods while leaving the nest unattended (Conway and Martin 2000a, b; Griffith et al. 2016). Reduced energy expenditure during incubation, and increased foraging time during the incubation period may positively affect parental condition, which in turns enables them to forage more effectively later while feeding nestlings, leading to improved nestling body condition (Griffith et al. 2016). Indeed, we showed that offspring from experimentally heated nests had larger body mass on day 12 in comparison to the control ones. Body mass at fledging was proposed as a reliable index of the survival probability for avian offspring (e.g., Magrath 1991). Also, in the study population of collared flycatchers, higher body mass at fledgling seem to be the most important trait affecting juvenile survival (Linden et al. 1992). Note that body mass at the day 12 were affected by many factors such brood size, hatching date and tarsus length. The results are in line with previous studies, which showed that these factors may explained the variation in body mass at the day 12 in these species (e.g., Linden et al. 1992; Merilä 1996). However, we did not show that our experimental manipulation affects offspring survival. We only found that female offspring experienced higher mortality than male offspring until day 12 after hatching. This result suggests that male and female nestlings differ in their sensitivity to some environmental or social conditions experienced in the nest during development. Moreover, we showed that offspring survival was correlated with the body mass at hatching: heavier nestlings experienced lower mortality at prefledgling period which indicates that larger size at hatching gives advantage in chances to survive up to leaving the nest.

Our results may suggest that higher temperature in the nest reduces an energetic cost of females during incubation and leads to re-allocation of resources into the post-hatching period. Unfortunately, our study design did not allow us to separate the effect of the heating treatment on eggs from the effects of being raised by a heated female, as cross-fostering procedure was not applied. However, we did not observe the elevated temperature in the nest box to affect egg incubation temperature. Moreover, since we did not observe that offspring from the experimentally heated nests had larger body mass at hatching in comparison to the control ones, the observed differences in body mass between control and experimental fledglings could be related to female behaviour. Indeed, previous work on birds have also shown that changes in energetic investment during one life-history stage can have carry-over effects on subsequent life-history stages within reproductive bouts (Heaney and Monaghan 1996; Pérez et al. 2008). Specifically, study on the tree swallow revealed that such an effect is probably due to the behaviour of heated females, as heated females provisioned their nestlings at a greater rate than did control females (Pérez et al. 2008).

In conclusion, given the obvious importance of temperature to embryo development and the female's response to experimentally altered temperature, the inconsistent relationships between ambient temperature and incubation behaviour in avian studies are still an enigma. Much more research is needed to understand how thermal environmental conditions affect incubation behaviour, and how their effects on fitness arise. Such insights will not only provide foundational information regarding avian evolution and ecology, but also contribute to avian conservation.

Acknowledgements We thank two anonymous referees for their constructive comments on an earlier version of this paper. We are grateful to the numerous people who assisted with fieldwork, and Barbara Reguera for helping with the experiment.

Author contributions AA and RM designed the experiments. WO, AD and RM, assisted by AA and SM, performed the field experiments. RM prepared data on incubation behaviour and carried out the statistical analyses. AA and RM wrote the first draft of the manuscript with all authors contributing to its preparation.

Funding This study was supported by the Ministry of Science and Higher Education of Poland: program 'Mobilność Plus' (program no. $1659 / \mathrm{MOB} / \mathrm{V} / 2017 / 0$ to AA). RM was supported by the Polish National Agency for Academic Exchange within a mobility scholarship of the Bekker programme (PPN/BEK/2019/1/00253). Part of fieldwork was supported by the Sonata Bis grant from National Science Centre (to SMD, Grant no. UMO-2015/18/E/NZ8/00505). 
Data availability Data will be made available from the Dryad Digital Repository on acceptance.

\section{Declarations}

Conflict of interest We have no conflicts of interest to report.

Ethical approval The data upon which this study are based have been obtained following the Swedish guidelines for work on natural populations and under a permit from the Swedish Ringing Centre at the Museum of Natural History in Stockholm (permit no. RC712).

Open Access This article is licensed under a Creative Commons Attribution 4.0 International License, which permits use, sharing, adaptation, distribution and reproduction in any medium or format, as long as you give appropriate credit to the original author(s) and the source, provide a link to the Creative Commons licence, and indicate if changes were made. The images or other third party material in this article are included in the article's Creative Commons licence, unless indicated otherwise in a credit line to the material. If material is not included in the article's Creative Commons licence and your intended use is not permitted by statutory regulation or exceeds the permitted use, you will need to obtain permission directly from the copyright holder. To view a copy of this licence, visit http://creativecommons.org/licenses/by/4.0/.

\section{References}

Álvarez E, Barba E (2014) Behavioural responses of great tits to experimental manipulation of nest temperature during incubation. Ornis Fenn 91(4):220

Amininasab SM, Kingma SA, Birker M, Hildenbrandt H, Komdeur J (2016) The effect of ambient temperature, habitat quality and individual age on incubation behaviour and incubation feeding in a socially monogamous songbird. Behl Ecol Sociobiol 70(9):15911600. https://doi.org/10.1007/s00265-016-2167-2

Andreasson F, Nord A, Nilsson J-Å (2018) Experimentally increased nest temperature affects body temperature, growth and apparent survival in blue tits nestlings. J Avian Biol 49(2):1-14. https://doi. org/10.1111/jav.01620

Ardia DR, Cooper CB, Dhondt AA (2006) Warm temperatures lead to early onset of incubation, shorter incubation periods and greater hatching asynchrony in tree swallows Tachycinetabicolor at the extremes of their range. J Avian Biol 37(2):137-142. https://doi. org/10.1111/j.0908-8857.2006.03747.x

Ardia DR, Pérez JH, Chad EK, Voss MA, Clotfelter ED (2009) Temperature and life history: experimental heating leads female tree swallows to modulate egg temperature and incubation behaviour. J Anim Ecol. https://doi.org/10.1111/j.1365-2656.2008.01453.x

Ardia DR, Pérez JH, Clotfelter ED (2010) Experimental cooling during incubation leads to reduced innate immunity and body condition in nestling tree swallows. Proc R Soc Lond B 277(1689):18811888. https://doi.org/10.1098/rspb.2009.2138

Bates D, Maechler M, Bolker B, Walker S (2015) Fitting linear mixedeffects models using lme4. J Stat Softw 67(1):1-48. https://doi. org/10.18637/jss.v067.i01

Berntsen HH, Bech C (2016) Incubation temperature influences survival in a small passerine bird. J Avian Biol 47(2):141-145. https://doi.org/10.1111/jav.00688

Biebach H (1986) Energetics of rewarming a clutch in starlings. Physiol Zool 59:69-75
Boulton RL, Richard Y, Armstrong DP (2010) The effect of male incubation feeding, food and temperature on the incubation behaviour of New Zealand robins. Ethology 116(6):490-497. https://doi.org/ 10.1111/j.1439-0310.2010.01759.x

Bryan SM, Bryant DM (1999) Heating nest-boxes reveals an energetic contraint on incubation behaviour in great tits, Parus major. Proc R Soc Lond B 266(1415):157-162. https://doi.org/10.1098/rspb. 1999.0616

Bueno-Enciso J, Barrientos R, Sanz JJ (2017) Incubation behaviour of Blue Cyanistes caeruleus and Great Tits Parus major in a Mediterranean habitat. Acta Ornithol 52(1):21-34. https://doi.org/10. 3161/00016454AO2017.52.1.003

Camfield AF, Martin K (2009) The influence of ambient temperature on horned lark incubation behaviour in an alpine environment. Behaviour 146:1615-1633. https://doi.org/10.1163/156853909X 463335

Capilla-Lasheras P (2018) incR: a new R package to analyse incubation behaviour. J Avian Biol 49:e01710. https://doi.org/10.1111/ jav.01710

Coe BH, Beck ML, Chin SY, Jachowski CM, Hopkins WA (2015) Local variation in weather conditions influences incubation behavior and temperature in a passerine bird. J Avian Biol 46(4):385394. https://doi.org/10.1111/jav.00581

Conway CJ, Martin TE (2000a) Evolution of passerine incubation behavior: influence of food, temperature, and nest predation. Evolution 54(2):670-685. https://doi.org/10.1111/j.0014-3820. 2000.tb00068.x

Conway CJ, Martin TE (2000b) Effects of ambient temperature on avian incubation behavior. Behav Ecol 11:178-188. https://doi. org/10.1093/beheco/11.2.178

Cresswell W, Holt S, Reid JM, Whitfield DP, Mellanby RJ (2003) Do energetic demands constrain incubation scheduling in a biparental species? Behav Ecol 14(1):97-102. https://doi.org/10.1093/ beheco/14.1.97

Deeming C (2002) Avian incubation: behaviour, environment and evolution. Oxford University Press

du Plessis KL, Martin RO, Hockey PAR, Cunningham SJ, Ridley AR (2012) The costs of keeping cool in a warming world: implications of high temperatures for foraging, thermoregulation and body condition of an arid-zone bird. Glob Change Biol 18:3063-3070

Dunn PO, Winkler DW, Møller AP (2010) Effects of climate change on timing of breeding and reproductive success in birds. In: Effects of climate change on birds, Oxford University Press, Oxford, pp 11

DuRant SE, Hopkins WA, Hepp GR, Walters JR (2013a) Ecological, evolutionary, and conservation implications of incubation temperature-dependent phenotypes in birds. Biol Rev 88(2):499-509. https://doi.org/10.1111/brv.12015

DuRant SE, Hopkins WA, Carter AW, Stachowiak CM, Hepp GR (2013b) Incubation conditions are more important in determining early thermoregulatory ability than posthatch resource conditions in a precocial bird. Physiol Biochem Zool 86(4):410-420. https:// doi.org/10.1086/671128

Griffith SC, Mainwaring MC, Sorato E, Beckmann C (2016) High atmospheric temperatures and 'ambient incubation'drive embryonic development and lead to earlier hatching in a passerine bird. R Soc Open Sci 3(2):150371. https://doi.org/10.1098/rsos.150371

Griffiths R, Double MC, Orr K, Dawson RJ (1998) A DNA test to sex most birds. Mol Ecol 7(8):1071-1075. https://doi.org/10.1046/j. 1365-294x.1998.00389.x

Halekoh U, Hojsgaard S (2014) A Kenward-Roger approximation and parametric bootstrap methods for tests in linear mixed modelsthe R package pbkrtest. J Stat Softw 59(9):1-30. https://doi.org/ 10.18637/jss.v059.i09

Halupka L, Halupka K (2017) The effect of climate change on the duration of avian breeding seasons: a meta-analysis. Proc R Soc Lond B (1867) 284:20171710. https://doi.org/10.1098/rspb.2017.1710 
Heaney V, Monaghan P (1996) Optimal allocation of effort between reproductive phases: the trade-off between incubation costs and subsequent brood rearing capacity. Proc R Soc Lond B 263(1377):1719-1724. https://doi.org/10.1098/rspb.1996.0251

Hepp GR, Kennamer RA, Johnson MH (2006) Maternal effects in Wood Ducks: incubation temperature influences incubation period and neonate phenotype. Funct Ecol. https://doi.org/10. 1111/j1365-2435,2006.01108.x

Hopkins BC, DuRant SE, Hepp GR, Hopkins WA (2011) Incubation temperature influences locomotor performance in young wood ducks (Aix sponsa). J Exp Zool A Ecol Genet Physiol 315(5):274279. https://doi.org/10.1002/jez.673

IPCC (2020) Climate change and land: synthesis report. Intergovernmental Panel on Climate Change, Geneva

Koski TM, Sirkiä PM, McFarlane SE et al (2020) Differences in incubation behaviour and niche separation of two competing flycatcher species. Behav Ecol Sociobiol 74:105. https://doi.org/10.1007/ s00265-020-02883-4

Kuznetsova A, Brockhoff PB, Christensen RHB (2017) lmerTest package: tests in linear mixed effects models. J Stat Softw 82(13):1-26. https://doi.org/10.18637/jss.v082.i13

Larsen VA, Lislevand T, Byrkjedal I (2003) Is clutch size limited by incubation ability in northern lapwings? J Anim Ecol 72(5):784792. https://doi.org/10.1046/j.1365-2656.2003.00751.x

Lenth R (2020) emmeans: estimated marginal means, aka least-squares means. $\mathrm{R}$ package version 1.4.6

Linden M, Gustafsson L, Part T (1992) Selection on fledging mass in the collared flycatcher and the great tit. Ecology 73(1):336-343. https://doi.org/10.2307/1938745

Lundblad CG, Conway CJ (2021) Intraspecific variation in incubation behaviours along a latitudinal gradient is driven by nest microclimate and selection on neonate quality. Funct Ecol. https://doi.org/ $10.1111 / 1365-2435.13772$

Magrath RD (1991) Nestling weight and juvenile survival in the Blackbird, TurdusMerula. J Anim Ecol 60:335-351. https://doi.org/10. $2307 / 5464$

Meehl GA, Zwiers F, Evans J, Knutson T, Mearns L, Whetton P (2000) Trends in Extreme Weather and Climate Events: Issues Related to Modeling Extremes in Projections of Future Climate Change. Bull Am Meteorol Soc 81(3):427-436. https://doi.org/10.1175/ 1520-0477(2000)081<0427:TIEWAC > 2.3.CO;2

Merilä J (1996) Genetic variation in offspring condition: an experiment. Funct Ecol 10(4):465-474. https://doi.org/10.2307/2389939

Nilsson JF, Stjernman M, Nilsson JÅ (2008) Experimental reduction of incubation temperature affects both nestling and adult blue tits
Cyanistescaeruleus. J Avian Biol 39(5):553-559. https://doi.org/ 10.1111/j.0908-8857.2008.04199.x

Nord A, Nilsson JÅ (2011) Incubation temperature affects growth and energy metabolism in blue tit nestlings. Am Nat 178(5):639-651. https://doi.org/10.1086/662172

Olson CR, Vleck CM, Adams DC (2008) Decoupling morphological development from growth in periodically cooled zebra finch embryos. J Morphol 269(7):875-883. https://doi.org/10.1002/ jmor. 10635

Pachauri R et al (2014) Climate Change 2014: Synthesis Report. 5 (2014)

Pautasso M (2012) Observed impacts of climate change on terrestrial birds in Europe: an overview. Ital J Zool 79(2):296-314. https:// doi.org/10.1017/CBO9781107415324

Pérez JH, Ardia DR, Chad EK, Clotfelter ED (2008) Experimental heating reveals nest temperature affects nestling condition in tree swallows (Tachycinetabicolor). Biol Lett 4(5):468-471. https:// doi.org/10.1098/rsbl.2008.0266

Perrins CM, McCleery RH (2001) The effect of fledging mass on the lives of great tits Parus major. Ardea 89(1):135-142

R Core Team (2020) R: a language and environment for statistical computing. R Foundation for Statistical Computing, Vienna. Available at: https://www.R-project.org/. Accessed 10 Nov 2020.

Radchuk V, Reed T, Teplitsky C et al (2019) Adaptive responses of animals to climate change are most likely insufficient. Nat Commun 10:3109. https://doi.org/10.1038/s41467-019-10924-4

Reid JM, Monaghan P, Ruxton GD (2000) Resource allocation between reproductive phases: the importance of thermal conditions in determining the cost of incubation. Proc R Soc Lond B. https:// doi.org/10.1098/rspb.2000.0963

Svensson L (1992) Identification guide to European passerines. L. Svensson

van de Ven TMFN, McKechnie AE, Er S et al (2020) High temperatures are associated with substantial reductions in breeding success and offspring quality in an arid-zone bird. Oecologia 193:225-235. https://doi.org/10.1007/s00442-020-04644-6

Vaugoyeau M, Meylan S, Biard C (2017) How does an increase in minimum daily temperatures during incubation influence reproduction in the great tit Parus major? J Avian Biol 48(5):714-725. https://doi.org/10.1111/jav.01208

Wickham H (2016) ggplot2: elegant graphics for data analysis. Springer-Verlag, New York

Publisher's Note Springer Nature remains neutral with regard to jurisdictional claims in published maps and institutional affiliations. 